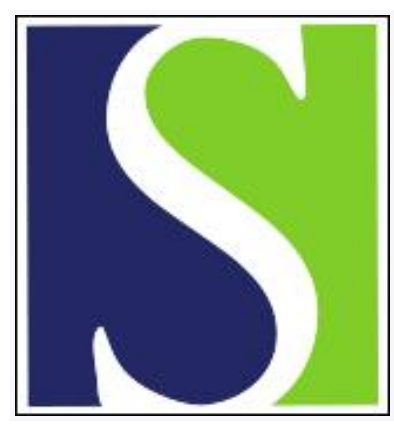

Scand J Work Environ Health 1985;11(3):165-171

https://doi.org/10.5271/sjweh.2240

Issue date: Jun 1985

Chloracne, "the hallmark of dioxin intoxication".

by Suskind RR

This article in PubMed: www.ncbi.nlm.nih.gov/pubmed/2930898

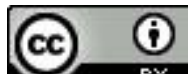

This work is licensed under a Creative Commons Attribution 4.0 International License 


\title{
Chloracne, "the hallmark of dioxin intoxication"
}

\author{
by Raymond R Suskind, MD
}

\begin{abstract}
SUSKIND R. Chloracne, "the hallmark of dioxin intoxication." Scand J Work Environ Health 11 (1985) 165-171. Clinical experiences and laboratory studies are described involving a population of workers who were exposed in a plant making $2,4,5$-trichlorophenoxyacetic acid $(2,4,5-\mathrm{T})$, including a trichlorophenol runaway reaction. Workers were followed for a period of four years, and 30 years later a mortality analysis was done on those exposed to runaway reaction material to determine possible increased risks for causes of death. Subsequently, a morbidity study on 436 employees involving three cohorts was carried out to determine the long-term health effects associated with the production of $2,4,5-\mathrm{T}$ including 2,3,7,8-tetrachlorodibenzo-p-dioxin (TCDD). The mortality and morbidity studies demonstrated that the standardized mortality ratio for all causes of death was 69 , and for cancer at all sites and cardiovascular disease it was 100 and 68 , respectively. The most significant observations emerging from the morbidity study were that $86 \%$ of the exposed persons developed chloracne at some time and that $52.7 \%$ still had chloracne on examination 20 to 30 years after the initial exposure. There appeared to be no evidence, on a long-term basis, of increased risks for cardiovascular disease, hepatic disease, renal disease, central and peripheral nerve problems, reproductive problems, or birth defects among the exposed and those who had chloracne among the exposed. Studies on the cell kinetics and pathogenesis of chloracne indicate that TCDD induces the modulation of undifferentiated sebaceous gland cells to keratinocytes. This action results in a disappearance of sebaceous glands and substitution of closed comedones and keratin cysts. Production workers have the highest frequency and severity of chloracne and systemic effects. Populations of users of 2,4,5-T rarely, if ever, develop chloracne, and there appear to be no welldocumented systemic effects. Among populations which live in accidentally or otherwise contaminated environments, there are only a limited number of chloracne cases and no well-documented systemic effects. Sufficient exposure to TCDD can induce chloracne, but systemic manifestations such as peripheral neuritis and transient hepatic dysfunction occur only in association with and subsequent to the appearance of chloracne. Chloracne is the hallmark of TCDD absorption and biological response in humans.
\end{abstract}

Key terms: cell kinetics; subacute, long-term health effects; systemic associations; 2,3,7,8-tetrachlorodibenzo-p-dioxin; TCDD.

The term "chloracne" has almost become a household word since the beginning of the "Agent Orange" controversy and since the incident at Seveso. Occupational physicians and dermatologists, however, have been aware of this syndrome since 1897 when it was first described by Von Bettman.

From the turn of the century to the early 1940s, numerous reports were published describing an acneform eruption, sometimes associated with systemic manifestations, in workers exposed to several chlorinated aromatic compounds. They included chlorinated naphthalene, chlorinated benzols, chlorinated diphenyls, chlorinated phenols, and other chlorinated hydrocarbons. These compounds were used for insulating, fireproofing, and Degaussing cables and as a dielectric in condenser manufacturing $(5,8$, $9,10,11,15,17,20,24)$. In the late 1940s some of these substances, especially the chlorinated phenols, were used as intermediates to make products such as herbicides, eg, 2,4,5-trichlorophenoxyacetic acid $(2,4,5-T)$, the bacteriostatic agent hexachlorophene, and the fungicide pentachlorophenol.

\footnotetext{
1 Institute of Environmental Health, University of Cincinnati, Cincinnati, Ohio, the United States.
}

Reprint requests to: Dr RR Suskind, Institute of Environmental Health, University of Cincinnati, 3223 Eden Avenue, Cincinnati OH 45267, USA.
There are several known causes of acneform eruptions in the workplace. They include crude petroleum cutting oils, coal tar and its derivatives, and the chlorinated aromatic compounds. Among the chlorinated aromatic compounds, the most potent appears to be 2,3,7,8-tetrachlorodibenzo-p-dioxin (TCDD). The other 21 isomers of this compound are less acnegenic. The rank order of their systemic toxicity in animals is better known than their rank order of acnegenicity. Other chlorinated dioxins, such as penta-, hexa-, and heptachlorinated dioxins, are also acnegenic. Some of these are found as contaminants in pentachlorophenol. In the case of the polychlorinated biphenyls, the active acnegenic agent is presumed to be the chlorinated dibenzofurans. In the past five years reports have been published regarding the acnegenicity of chlorinated azobenzene and azoxybenzene compounds $(12,23,25)$. These are also found as contaminants in the preparation of herbicides, in which 3,4-dichloroaniline has been used as in the preparation of the herbicides diuron, linuron, propanil, and neburon. Hence, if the oxygen linkage of the dioxin is substituted with nitrogen, the chlorinated azo compound continues to be acnegenic.

My own personal experience with TCDD began in October 1949, when my colleagues and I, at the Kettering Laboratory, were asked to examine four workers who had become ill following an industrial process 

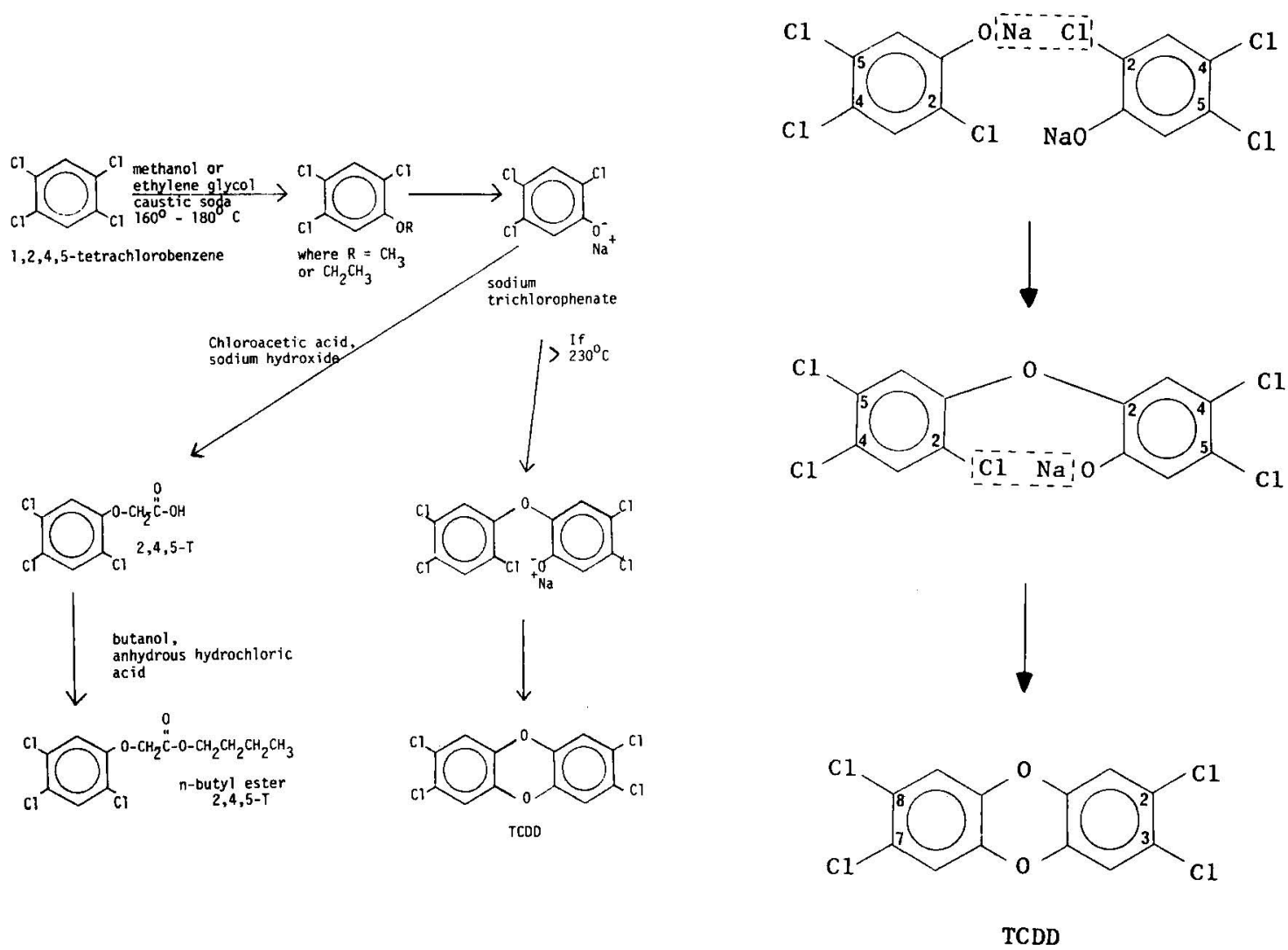

Figure 1. Synthesis of 2,4,5-trichlorophenoxyacetic acid and the condensation reaction of trichlorophenol to 2,3,7,8-tetrachlorodibenzo-p-dioxin.

accident which occurred in March of that year in a plant making 2,4,5-T. A kettle, in which trichlorophenol was being made, overheated and developed excessive pressure. Part of the contents was emitted through a safety valve and broken pipe connector into the plant building and its surroundings. We did not know it at the time, but $2,3,7,8$-TCDD was a toxic component of the kettle contents. Figure 1 describes the synthesis of 2,4,5-T and the condensation reaction of trichlorophenol to TCDD.

The employees involved in the clean-up of that building and the restoration of equipment developed acute symptoms involving the respiratory tract; they also complained of skin and eye irritation, headache, dizziness, and nausea. These symptoms subsided within one to two weeks. They were followed by an acneform eruption; severe muscle pain affecting the extremities, thorax and shoulders; fatigue; nervousness and irritability; dyspnea; complaint of decreased libido; and intolerance to cold. The first four persons we examined had severe generalized chloracne (figures $2 \mathrm{a}, 2 \mathrm{~b}$ and $2 \mathrm{c}$ ), hepatic tenderness and enlargement, peripheral neuritis, a delayed prothrombin time, and an increase in total serum lipids (3). Transaminase tests were not developed at that time. Histological examination of a nerve biopsy in a worker with pedal sensory loss showed a myelin degeneration which we assumed was related to his neuropathy.

The four were reexamined in six months, and eventually a total of 36 subjects were followed, in a series of examinations, until 1953 (26). By that time, the symptoms and findings observed as initially referable to the liver and nervous system had subsided. There was some persistence of the acne, but considerable improvement was noted in most cases. A variety of treatments was used at the time by local physicians.

It was in 1957 that the toxic contaminant of the $2,4,5$ - $T$ process was identified as $2,3,7,8$-TCDD. A considerable amount of research has been carried out in the last 15 years on the nature of its toxic action in animals. It is now known to be the most potent acnegen on record.

One of our interests in the early 1950 s was to determine which of the several trichlorophenol production processes were acnegenic and which were not. We were provided with trichlorophenol from three different processes. They included (i) sodium trichlorophenate from the process of the affected plant, (ii) the same material after distillation, and (iii) a sample from another company's process using dilution and filtration. The positive control substance was Halowax 1014, a mixture of hexa- and pentachloro- 


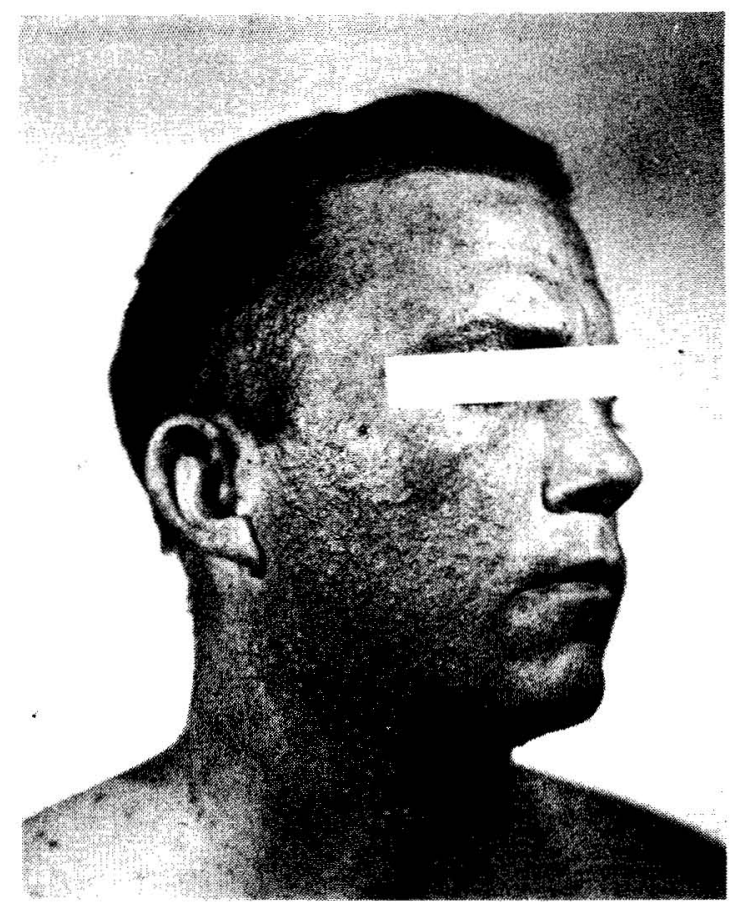

Figures 2 a, b \& c. Examples of the severe generalized chloracne seen in four persons examined in 1949.

naphthalene. Prior to this time, we had attempted to induce pilosebaceous changes in a variety of experimental animals, but were not successful. We were familiar with Dow Chemical's rabbit ear test. We did not believe at the time that the results were specific enough to translate into human experience.

A study was conducted in 1953 with these materials. Our test subjects were 12 human volunteers. Each material was made up in a nonwater-absorbing vehicle (Plastibase ${ }^{\odot}$ ), which was not acnegenic, and, by testing the materials on ourselves and rabbits, we determined the threshold irritant and nonirritant concentrations of each of the materials.

These materials were then applied in measured quantities to the flexural surface of the forearm of the subjects, daily for six weeks. The concentrations were as follows: (i) $3.5 \%$, (ii) $7.0 \%$, (iii) $3.5 \%$, and Halowax $20 \%$. Three subjects were exposed to each
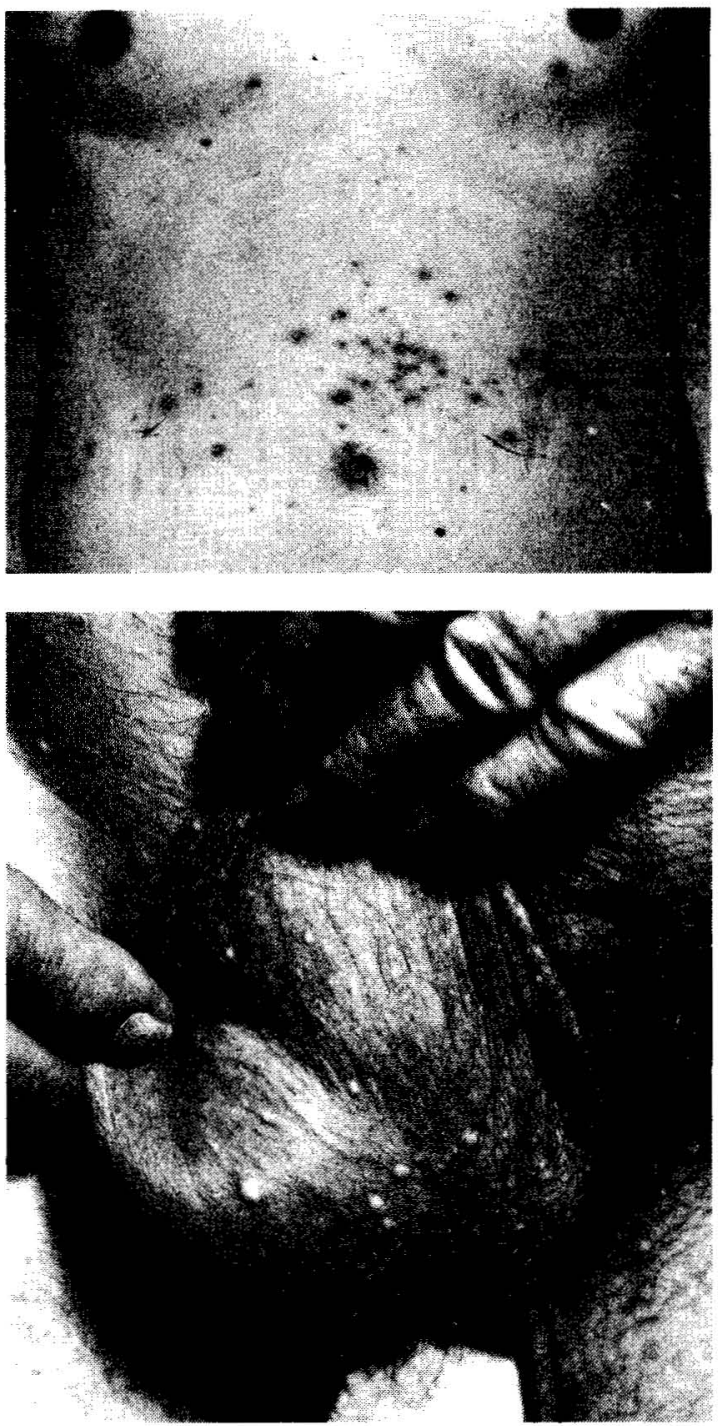

material. The skin sites were examined daily for gross changes. Serial biopsies were taken on the subjects prior to exposure, at intervals during the exposure period, and finally six weeks after the last exposure. The subjects were given physical examinations and liver function tests prior to and at two-week intervals during the exposure and at 12 weeks after the exposure.

The sequence of cellular events in the evolution of chloracne, as induced by the material from the original plant process, are shown in the photomicrographs which are summarized in figures $3 a, 3 b$ and $3 c$. The first indication of change is hyperkeratinization in the sebaceous gland duct. This occurrence is followed by plugging of the follicular orifice, which occurs simultaneously with the alteration of the differentiation process of the acinar cells. These cells, which are undifferentiated at the periphery, normally differen- 
A.

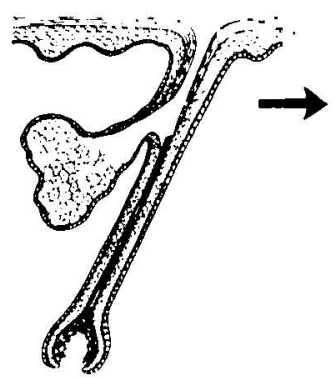

в.

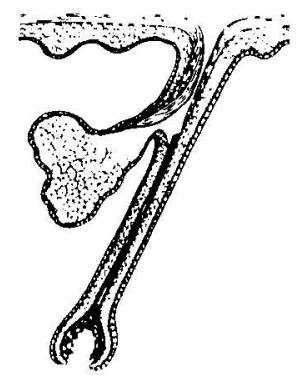

c.
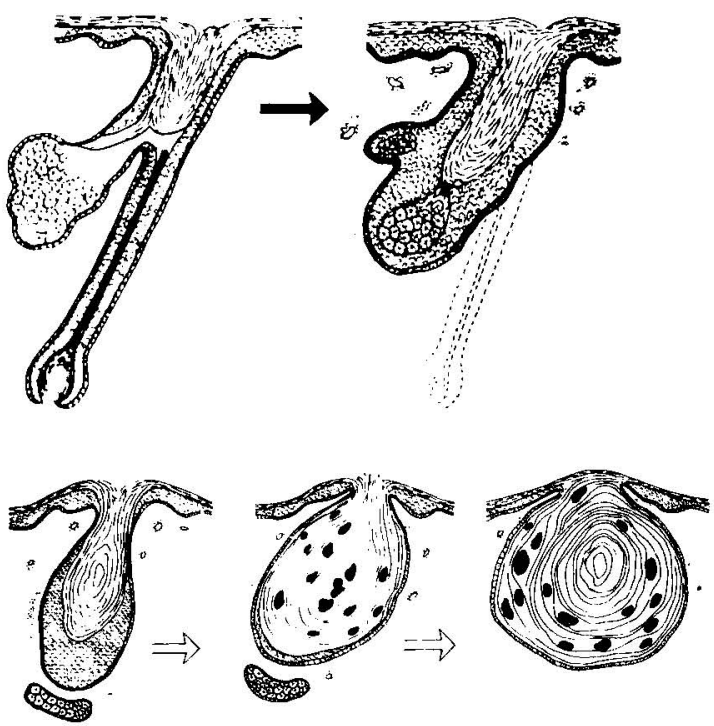

Figures 3 a, b \& c. Sequence of events in the evolution of chloracne.

tiate into sebaceous or lipid-producing cells. The effect of the toxic agent is to cause the undifferentiated cells to become keratinocytes, which produce keratin. The pathologist interprets this change as the disappearance of the sebaceous glands and the formation of a closed comedone, frequently termed retention cysts. What is most interesting is that, in some cases, no matter what the original severity of the chloracne following the cessation of exposure, the complete pilosebaceous structure, including the sebaceous gland, is restored. The sequence of pilosebaceous changes induced by the plant trichlorophenate was the same as that induced by Halowax 1014.

No abnormal clinical (other than the skin) changes or abnormal laboratory findings were observed in any of the subjects during the exposure or the follow-up period.

Now, what about experimental chloracne with TCDD in animals? The skin of the pinna of the rabbit ear has been used as a screening model for chloracnegens since 1941 and is still widely used (1). Assessment of acnegenicity is made on the basis of clinical examination and histologic examination for epidermal hyperplasia, comedones, and epithelial cysts. Several modifications have been suggested, including the use of the skin of the external canal of the rabbit, which is richest in sebaceous structures, instead of the pinna. Inagami and his colleagues (13) applied chlorinated biphenyl-contaminated rice oil responsible for the Yusho epidemic in Japan to hairless mice and reported follicular hyperkeratotic changes in the sebaceous follicles. Recently, the hairless mouse was explored as a model for testing potential acnegens by Puhvel (22) using two different mouse strains. $2,3,7,8-T C D D$ was reported to produce all of the skin changes seen in chloracne in man, including hyperkeratinization of the stratum corneum and disappearance of sebaceous gland follicles in the formation of keratin cysts. These occurrences were identical to those produced by Halowax 1014, which we studied as well about 30 years ago in humans.

At least three groups have studied TCDD effects in monkeys. McConnell et al (18), after administering lethal doses of TCDD to Rhesus monkeys, observed the development of acneform lesions on the lips, retention cysts of the Meibomian glands of the eyelids, facial alopecia, and loss of eyelashes. Allen and his group (2) observed similar changes in Rhesus monkeys who were fed a diet of 500 parts per trillion of TCDD for nine months. Such levels were found to be toxic for the animals, and the majority of them died. Unfortunately, threshold levels for acnegenicity in animals, as well as in man, have not been established. However, the most heavily exposed populations, which are industrial workers, demonstrate that chloracne may be the only adverse clinical finding when the exposure is limited. On the other hand, following runaway reactions such as occurred in West Virginia, in the Netherlands, in the United Kingdom and in West Germany, it was only among some of the workers who developed chloracne that involvement of other organ systems was observed. This also occurred in workers heavily exposed to the $2,4,5$ - $\mathrm{T}$ manufacturing process but not to a runaway reaction, as in Spolano, Czechoslovakia.

Next I want to consider what is known about longterm health effects in humans. In 1978, we were able to identify 122 workers who had been exposed to the trichlorophenol runaway reaction which affected the original four. A standard mortality analysis was conducted on 121 workers in this group (30). As of 1979, the standardized mortality ratio for all causes of death was 69 with 32 deaths observed and 46.41 expected. For the categories of cancer and cardiovascular diseases, the corresponding ratios were 100 and 68 , respectively. Because of the small size of the cohort and small numbers of deaths, the results cannot be regarded as conclusive, but they suggest no significant difference from expected death rates. Here is a 
cohort which was heavily exposed to TCDD. Disabling health effects were observed in many but not all, acutely, subacutely, and subchronically. If risk were substantial for hepatic, cardiac, or pulmonary disease and cancer, we should have detected it even in this small cohort. One of this group of 32 died of a malignant fibrous histiocytoma, originating in the skin. It is classified as a soft tissue sarcoma. Another, not in this accident group but exposed to the process and who had chloracne, died of a liposarcoma. The frequency data of soft tissue sarcomas for the general population is inadequate since those occurring in specific organ systems are classified under the International Classification of Disease number for tumors of the stomach or central nervous system or kidney or wherever they are found. The causal association of soft tissue sarcomas and TCDD is still to be determined.

In June of 1979, we returned to the same plant and carried out a clinical study on 436 employees to determine and identify the possible long-term effects of chemicals associated with the production of 2,4,5-T, including TCDD, and to determine the increased risk for the adverse effects which have been observed in the subacute phase in man, as well as those noted in experimental animals (27). The examination program attempted to determine possible increased risks for cutaneous, pulmonary, cardiovascular, gastrointestinal, hepatic, renal and neurobehavioral problems, reproductive and birth defect problems, and effects on lipid metabolism. The population included those exposed to the process accident in 1949, as well as those exposed to the normal processes of manufacturing in the period 1948-1969, and it included chemical operators, service employees, such as pipefitters, mechanics, etc. The controls (referents) were never associated in any way with the 2,4,5-T process or its materials. The cohorts consisted of the following persons: $204 \mathrm{ex}-$ posed, 163 not exposed, and 51 of questionable exposure.

In this study, we found that $86 \%$ of the exposed had developed chloracne and $52.7 \%$ of the exposed, on examination, still had chloracne. None of the not exposed or the questionably exposed ever developed chloracne. There appeared to be an association between the persistence of chloracne and the presence and severity of elastic tissue degeneration of the skin, as found in actinic elastosis. There also appeared to be an association between exposure and the history of gastrointestinal tract ulcer. The occurrence of ulcers in the upper part of the gastrointestinal tract of the exposed was four times that of the not exposed. We also found that pulmonary function values among the exposed who currently smoked were lower than those who were not exposed and currently smoked. If one compared pulmonary function values of the exposed to those of the not exposed, there was a significant difference, and, when one considered pulmonary function in relation to smoking (past, present or never), it was only the present smokers who had a greater frequency of lower pulmonary function values. There appeared to be no evidence of increased risk among the exposed and those who had chloracne among the exposed for the following: cardiovascular disease, hepatic disease, renal disease, central or peripheral nerve problems, reproductive problems, or birth defects. There was a significantly greater number of subjects with low levels of highdensity lipoprotein in those with persistent chloracne than in those with a history only of chloracne or those who had never had chloracne. However, when the mean lipid levels for these three chloracne groups were compared, no significant differences were found.

Finally I would like to turn to the subject of how effects in production workers compare to those in other types of exposed populations. Populations potentially exposed to the chlorinated dioxins or dibenzofurans include production workers, formulators and users (sprayers) of herbicides, and those living in areas contaminated with the toxic agent through spraying or through inappropriate use of materials contaminated with dioxins.

Among the production workers, the frequency and severity of chloracne is related to the degree and extent of exposure, and the systemic manifestations attributed to the exposure always follow the appearance of chloracne. The degree and extent of exposure may also reflect involvement in a runaway reaction as in one industry in the United States (30), in one plant in Germany (28), in one plant in the United Kingdom (16), and in one in the Netherlands (6). The systemic manifestations may be clinical, as in the case of peripheral neuritis, and/or determined by laboratory findings, eg, elevated lipids and liver profile enzymes. In workplace exposures in which the plant hygiene was relatively good, as in the case of a Midland, Michigan, population, the frequency and severity of chloracne was low and systemic effects infrequent.

We now recognize that porphyria in humans, including the cutaneous manifestations of porphyria cutanea tarda, have only been observed in two production worker populations. These populations account for less than $10 \%$ of the production population groups. They were the groups observed by Bleiberg and his colleagues (4) and subsequently by Poland and his co-workers (21) and the workers at Spolano reported by Jirasek and his colleagues (14). In both instances, it was a mixed exposure to 2,4,5-T and 2,4-dichlorophenoxyacetic acid processing. In the Spolano plant there was also a heavy exposure to pentachlorophenol. In the group studied by Bleiberg et al, of the 26 workers whose urine was tested for uroporphyrins, 8 had elevated uroporphyrins and 19 had chloracne. Three with elevated uroporphyrins had no chloracne. Exposure to relatively pure TCDD in a laboratory accident, reported by Oliver (19), did 
not produce porphyria. Another workplace exposure which resulted in an $86 \%$ frequency of chloracne and systemic manifestations, including transient hepatic damage, as in the West Virginia group, did not result in porphyria.

Among the sprayer user population in the United States, which started in 1948, there have been no reports of chloracne or systemic effects. 2,4,5-T, which was known to contain varying amounts of $2,3,7,8-T C D D$, was widely used in large-scale farming, family gardens, forest management, and for weed control along roadsides and railroad rights-ofway. The extent of the human exposure in the United States can be gauged by the statistic for the year 1964, in which 9.8 million pounds (about $45 \cdot 10^{4}$ metric tons) were produced for domestic use alone. In the case of the most heavily exposed sprayers in Viet Nam, the Ranch Hand group of the Air Force (29), a carefully conducted epidemiologic and morbidity study completed this year has demonstrated no evidence of chloracne and no conclusive evidence of systemic problems.

Among the studies of populations exposed to a contaminated community environment, those of Seveso and Times Beach, Missouri, contribute significantly to our knowledge. The acute effects on residents and domestic animals living near the plant at Seveso, which experienced a trichlorophenol runaway reaction, are well documented. The most significant finding in humans was chloracne, especially in children. While some peripheral nerve and liver impairment was reported within the first two years after the incident, no chronic long-term systemic effects have been documented, and the study of these effects continues. The Center for Disease Control (CDC) and the Missouri Division of Health conducted a clinical examination of residents in the heavily contaminated Times Beach area (7). No cases of chloracne were found nor any increased disease prevalence of any kind.

We were curious about any unusual characteristics of the group of exposed workers who did not develop chloracne in our study. They constituted $14 \%$ of the exposed. Their job categories included production operator, helpers, miller, dryer, grinder, bagger, mechanic, pipefitter, and process research chemist. Their duration of exposure ranged from 1.5 to 96 months. Their ages ranged from 36 to 68 years. Their life-styles and hygienic practices were different. Among those who had chloracne $16.5 \%$ never smoked; among those who did not develop chloracne $39.3 \%$ never smoked. The frequency of using protective gear, washing, and bathing in this group appeared to be greater than among those who developed chloracne. These differences may or may not account for the difference in clinical response. I believe that, in this group, individual susceptibility may also have been a factor.
In summary, I have attempted to describe the kinds of chlorinated hydrocarbon work exposures which result in chloracne and my own experience with TCDD-exposed work populations, including the frequency and severity of chloracne as a subacute or subchronic manifestation of intoxication. The involvement of other organ systems which may be associated with chloracne, the cellular kinetics of chloracne, and the long-term effects in a substantially TCDD-exposed population have been discussed. It has been demonstrated that production workers have the highest frequency and severity of chloracne. Some sustain systemic injury which, while temporary, occurs only in persons who have developed chloracne. The populations of users which have been studied carefully rarely, if ever, develop chloracne, and there appear to be no well-documented systemic effects. Among those populations which live in accidentally or otherwise contaminated environments, well-documented studies show a very limited number with chloracne and no documented systemic effects. It is from these observations that one can state that chloracne is indeed a hallmark not only of TCDD absorption and biological response in humans, but it is also a hallmark of TCDD intoxication.

\section{References}

1. Adams EM, Irish DD, Spencer HC, Rowe VK. The response of rabbit skin to compounds reported to have caused acneform dermatitis. Ind Med Ind Hyg Sect 2 (1941) 1-4.

2. Allen JR, Barsotti DA, Van Miller JP, Abrahamson LJ, Lalich JJ. Morphological changes in monkeys consuming a diet containing low levels of 2,3,7,8-tetrachlorodibenzo-p-dioxin. Food Cosmet Toxicol 15 (1977) 401-410.

3. Ashe WF, Suskind RR. Reports on chloracne cases, Monsanto Chemical Company, Nitro, West Virginia. Kettering Laboratory, Cincinnati, OH 1949 \& 1950. (Reports of the Kettering Laboratory December 1949 \& April 1950).

4. Bleiberg J, Wallen M, Brodkin R, Applebaum IL. Industrially acquired porphyria. Arch Dermatol 89 (1964) 793-797.

5. Collier E. Poisoning by chlorinated naphthalene. Lancet 1 (1943) 72-74.

6. Dalderup LM. Safety measures for taking down buildings contaminated with toxic materials. J Soc Geneesk 52 (1974) 582-585, 616-623.

7. Donnel HD, Hoffman RE. Pilot study Times Beach Missouri. Presentation at meeting of AMA CSA Advisory Panel on Toxic Substances, 13 December 1983.

8. Fulton WB, Matthews JL. A preliminary report on dermatological and systemic effects of exposure to hexachloronaphthalene and chlorodiphenyl. Pennsylvania Department of Labor and Industry, Harrisburg, PA 1936, pp 1-15. (Special bulletin no 43).

9. FUSS. Chloracne. Tagung d Vereinig Suedwestdeutsch Dermat, Heidelburg 1936. (Report 62).

10. Good CK, Pensky N. Halowax acne ("cable rash"): A cutaneous eruption in marine electricians due to certain chlorinated naphthalenes and diphenyls. Arch Dermatol Syphilol 48 (1943) 251-257.

11. Greenberg L, Mayers MR, Smith AR. The systemic 
effects resulting from exposure to certain chlorinated hydrocarbons. J Ind Hyg Toxicol 21 (1939) 29.

12. Hill RH Jr, Rollen ZJ, Kimbrough RD, Groce DF, Needham LL. Tetrachloroazobenzene in 3,4-dichloroaniline and its herbicidal derivatives: Propanil, diuron, linuron, and neburon. Arch Environ Health 36 (1981) $11-14$.

13. Inagami $\mathrm{K}$, Koga $\mathrm{T}$, Kikuchi $\mathrm{M}$, Hashimoto $\mathrm{M}$, Takahashi H, Wada K. Experimental study of hairless mice following administration of rice oil used by a Yusho patient. Fukuoka Igaku Zasshi 60 (1969) 548-553.

14. Jirasek L, Kalensky J, Kubec K. Acne chlorina and porphyria cutanea tarda during the manufacture of herbicides: Part I. Cesk Dermatol 48 (1973) 306-315.

15. Kelley EF. Acne from synthetic wax (Halowax). Urol Cutaneous Rev 47 (1943) 238-239.

16. May G. Chloracne from the accidental production of tetrachlorodibenzodioxin. $\mathrm{Br} \mathrm{J}$ Ind Med 30 (1973) 276-283.

17. Mayers MR, Silverberg MG. Skin conditions resulting from exposure to certain chlorinated hydorcarbons. J Ind Hyg Toxicol 20 (1938) 244-258.

18. McConnell EE, Moore JA, Dalgard DW. Toxicity of 2,3,7,8-tetrachlorodibenzo-p-dioxin in Rhesus monkeys (Macaca mulatta) following a single oral dose. Toxicol Appl Pharmacol 43 (1978) 175-187.

19. Oliver RM. Toxic effects of 2,3,7,8-tetrachlorodibenzo-1,4-dioxin in laboratory workers. $\mathrm{Br} \mathrm{J}$ Ind Med 32 (1975) 49-53.

20. Peck SM. Dermatitis from cutting oils, solvents and dielectrics, including chloracne. J Am Med Assoc 125 (1944) 190-196.

21. Poland A, Glover E, Kende AS, DeCamp M, Giandomenico CM. 3,4,3',4'-Tetrachloro azoxybenzene and azobenzene: Potent inducers of aryl hydrocarbon hydroxylase. Science 194 (1976) 627-630.

22. Puhvel SM, Sakamoto M, Ertl DC, Reisner RM. Hair- less mice as models for chloracne: A study of cutaneous changes induced by topical application of established chloracnegens. Toxicol Appl Pharmacol 64 (1982) 492-503.

23. Scarisbrick DA, Martin JV. Biochemical changes associated with chloracne in workers exposed to tetrachloroazobenzene and tetrachloroazoxybenzene. J Soc Occup Med 31 (1981) 158-163.

24. Schwartz L. Occupational acne. NY State J Med 43 (1943) $1711-1718$

25. Sundstrom G, Jansson B, Renberg L. Determination of the toxic impurities 3,3',4,4'-tetrachloroazobenzene and $3,3^{\prime}, 4,4^{\prime}$-tetrachlorozoxybenzene in commercial diuron, linuron and 3,4-dichloroaniline samples. Chemosphere 7 (1978) 973-979.

26. Suskind RR. A clinical and environment survey, Monsanto Chemical Company, Nitro, West Virginia. Kettering Laboratory, Cincinnati, OH 1953. (Report of the Kettering Laboratory July 1953).

27. Suskind RR, Hertzberg VS. Human health effects of 2,4,5-T and its toxic contaminants. J Am Med Assoc 251 (1984) 2372-2380.

28. Thiess AM, Frentzel-Beyme R, Link R. Mortality study of persons exposed to dioxins in a trichlorophenol-process accident that occurred in the BASF AG on November 17, 1953. Am J Ind Med 3 (1982) 179-189.

29. US Air Force, School of Aerospace Medicine. Project ranch hand II: An epidemiological investigation of health effects on Air Force personnel following exposure to herbicides; baseline mortaliy studies. Brooks Air Force Base, US Air Force School of Aerospace Medicine, Texas 1983.

30. Zack JA, Suskind RR. The mortality experience of workers exposed to tetrachlorodibenzodioxin in a trichlorophenol process accident. J Occup Med 22 (1980) $11-14$. 